\title{
Modeling Efficiency Factor of Fly Ash in Concrete Using an Unification Approach
}

\author{
I-Cheng Yeh
}

\begin{abstract}
A quantitative understanding of the efficiency of fly ash as a mineral admixture in concrete is essential for its effective utilization. To overcome the disadvantages of traditional decomposition approaches, we proposed a novel unification approach. In this approach, using nonlinear regression and optimization technique, the compressive strength model and the efficiency factor model are generated at the same time. That is, the efficiency factor model is a part of the compressive strength model. The efficiency factor model reported could be helpful in the design of fly ash concretes at different age, at different replacement percentage, and different water-binder ratio with greater confidence.
\end{abstract}

Index Terms-Efficiency factor, fly ash, concrete, age, replacement percentage.

\section{INTRODUCTION}

Supplementary cementitious materials, consisting mainly of fly ash or ground blast furnace slag, have been considered in the production of high-performance concrete [1]-[2]. Fly ash is now recognized as a desirable cementitious ingredient of concrete, and as a valuable cement-replacement material, partly for reasons of economy and partly because of technical benefits imparted by the material. These materials can help control the temperature rise in concrete at early ages and may reduce the water demand for a given workability. However, early strength gain of the concrete may be decreased. The strength development of fly ash concrete has a great consideration for the scheduling of formwork removal [3]-[6].

Fly ash has been commonly used to replace part of cement in concrete, and the percentage of replacement ranges from about 10 to $20 \%$ (low volume fly ash) to more than $50 \%$ (high volume fly ash) of the total mass of cementitious materials. In low volume fly ash concrete, the fly ash acts as a pozzolanic material. In high volume fly ash concrete, only part of the fly ash participates in the pozzolanic reaction; the other part remains unreacted even after a long period of curing [4]-[6].

A quantitative understanding of the efficiency of fly ash as a mineral admixture in concrete is essential for its effective utilization. It is true that the uses of fly ash and superplasticizer change the composition of concrete. However, the water-cement ratio concept should be disposed of for the simple reason that there is nothing better to offer either for strength prediction or mixture proportioning. It is

Manuscript received February 28, 2013; revised June 17, 2013. This work was supported in part by the National Science Council of the R.O.C. (Taiwan) (Project No: NSC-101-2221-E-032 -044).

I-Cheng Yeh is with the Department of Civil Engineering, Tamkang University, New Taipei City, Taiwan (e-mail: 140910@mail.tku.edu.tw). more reasonable to modify the strength-versus-w/c relationship under the present, sophisticated circumstances [7]-[10].

The cementing efficiency of a pozzolan is defined as the number of parts of cement that could be replaced by one part of pozzolan without changing the property being studied. The efficiency of fly ash was estimated by trying to bring together the water cementitious material ratio to strength relations for both normal and fly ash concrete. In principle this was done by using the efficiency factor concept, which attempts to bring the water cementitious materials ratio nearer to the water cement ratio of the control concrete by applying the cementitious efficiency of fly ash " $k$ " at any particular strength. Thus the water cement ratio to strength relation of normal concretes will be the same for fly ash concretes, by considering the "water to effective cementitious materials ratio".

Efficiency factor concepts have been investigated by several researchers. From the numerous tests performed, correlations have been established between the $k$ and age and fly ash replacement percentage. These correlations are usually directly derived from simple statistical analysis of large quantities of experimental data from different sources. However, the approach is complicated by the fact that the value of the cement efficiency factor for a given fly ash is not constant, but varies depending on age, the cement used, curing conditions, and the nominal strength level at which the mix was designed.

Existing mix proportioning methods for fly ash concretes can be grouped into three categories: simple replacement methods, modified replacement methods, and efficiency factor replacement methods. Concretes designed by efficiency factor replacement methods are batched using fly ash with an efficiency factor in an attempt to produce the same strength development. In the efficiency factor replacement methods, each fly ash is considered to have its own unique "cement efficiency factor" that, in principle, compares the relative strength-gain potential of the fly ash on a weight for weight basis to that of normal portland cement. Such an assumption allows for the use of the well-known strength relations between the strength and water-cement ratio (w/c) in the design of fly ash mixes [5]-[7].

Babu and Rao made a comprehensive study of the design of fly ash concretes [8]. They studied the cementing efficiency of fly ash relative to cement as measured by the effect of the ash on the water-cement ratio. It was suggested in their study, considering the fact that the two concretes (with or without fly ash) can be made to reach the same strength at a given age by adjusting their water-cementitious material ratios, that the effect on water-cement ratio of a weight $F$ of fly ash will be equivalent to a weight $k F$ of 
cement where $k$ is an efficiency factor. Therefore, the efficient water-cementitious material ratios can be written in the following form

$$
\frac{W}{C+k_{S} \cdot S+k_{F} \cdot F}
$$

where $W$ is water content; $C$ is cement content; $S$ is GBFS content; $F$ is fly ash content; $k_{S}$ and $k_{F}$ are efficiency factors for GBFS and fly ash, respectively.

Their study was an effort directed towards a specific understanding of the efficiency of fly ash in concrete, considering the strength to water cement ratio relations, age and percentage of replacement. After a thorough evaluation, a set of value was proposed for $k$ at various ages from 7 to 90 days, and with various percentages of replacement from $15 \%$ to $75 \%$, and the range of $k$ proposed is rather wide. For example, a value of 0.13 at the age of 7 days with $75 \%$ percentage of replacement and; on the other hand, a value of 1.40 at the age of 90 days with $15 \%$ percentage of replacement for $k$.

A literature search was conducted. Rather than compiling an exhaustive annotated bibliography of the available literature, some important publications were reviewed, and they are listed in the References at the end of the paper [4]-[10]. Some theoretical and experimental studies have concentrated on concrete with fly ash, and test results have shown that the efficiency factor depends on two factors, age and replacement percentage of fly ash.

It was felt that the different conclusions drawn by the above investigators and even by many others earlier were all based on limited experimental investigations. It was thus decided to build strength models to assess the effect of fly ash on compressive strength at different ages over a wide range of water cementitious materials ratios and percentage replacement. To overcome some disadvantages of traditional decomposition approach to build the efficiency factor model, we proposed a novel unification approach, which can build the compressive strength model and the efficiency factor model at the same time.

The present paper deals with the efficiency of fly ash in concrete, through the strength to water cement ratio relations of these concretes at different ages, from 3- to 365-day, at the varying percentages of replacement, from 0 to $50 \%$, and at water-cementitious material ratios, from 0.3 to 0.7 .

\section{Methodology}

Most researchers adopt the decomposition approaches to study the efficiency factors. They first obtained the efficiency factors for a concrete sample through compare the concrete with and without fly ash. Second, they built the age efficiency factor $\left(k_{a}\right)$ model. Third, they built the "percentage efficiency factor" $\left(k_{p}\right)$ model. The "overall cementing efficiency" of fly ash is thus the product of $k_{a}$ and $k_{p}$ [8].

Although the decomposition approaches can build the efficiency factor models; however, this approach has two disadvantages. First, because the strength test of concrete is not very accurate, it is rather difficult to obtain the efficiency factor for a concrete sample through compare the concrete with and without fly ash. Second, when there are two types of supplementary cementitious materials, such as GBFS and fly ash, it is difficult to respectively build the percentage efficiency factor models for the two materials.

To overcome the two disadvantages of traditional decomposition approaches, we proposed a novel unification approach. In this approach, using nonlinear regression and optimization technique, the compressive strength model and the efficiency factor model are generated at the same time. That is, the efficiency factor model is a part of the compressive strength model. To compare the effects of the approach, we also proposed two simpler models, the threeand the five-parameter model. In these models, the logarithm type function is adopted as the time factor, and the exponential type function is adopted as the water-to-binder ratio factor.

Model 1. Three parameter model (without efficiency factors)

$$
f_{c}^{\prime}=(a \cdot \ln T+b) \cdot\left(\frac{W+S P}{C+S+F}\right)^{c}
$$

Model 2. Five parameter model (with constant efficiency factors)

$$
f_{c}^{\prime}=(a \cdot \ln T+b) \cdot\left(\frac{W+S P}{C+k_{S} \cdot S+k_{F} \cdot F}\right)^{c}
$$

Model 3. Night parameter model (with various efficiency factors)

$$
f_{c}^{\prime}=(a \cdot \ln T+b) \cdot\left(\frac{W+S P-k_{w}}{C+k_{S} \cdot S+f_{k_{F}} \cdot F}\right)^{c}
$$

where the efficiency factor of fly ash is a function of age $T$ and replacement percentage $R$, that is

$$
\begin{gathered}
f_{k_{F}}=k_{1}+k_{2} \cdot \ln T+k_{3} \cdot R+k_{4} \cdot R^{2} \\
R=\frac{F}{C+S+F}
\end{gathered}
$$

Fitting the above strength model with data of concretes with and without additional binder, these models can be built. Because these models are nonlinear, traditional linear regression cannot solve them. Optimization technique can be employed to minimize the sum of squared error of these models to obtain the parameters in these models. Because in Model 3 the efficiency factor $k_{F}$ is a part of the compressive strength model, after the model was built, the efficiency factor model can be derived.

\section{RESULTS}

In this study, the database available on the UCI Machine Learning Repository containing 1030 compressive strength 
data [1] were used to evaluate the above strength formulas. Each data includes the amounts of cement, blast furnace slag, fly ash, water, superplasticizer (SP), coarse aggregate(CA), fine aggregate(FA) (in kilograms per cubic meter), the age (in days), and the compressive strength (in psi).

Table I presents the general details of the concretes evaluated in this study. It was made sure that these will form a fairly representative group governing all the major parameters that influence the behavior of fly ash in concrete and present the complete information required for such an evaluation. The database only contains normal size aggregates (smaller than $20 \mathrm{~mm}$ ), normal superplasticizers content, normal curing conditions, etc.

However, the database also contains unexpected inaccuracies, for instance, the class of fly ash is sometimes not reported. The greatest difficulty seems to be related to the application of superplasticizers. They are used from different manufacturers, of different chemical composition, and without details concerning solid contents in the suspension.

Fitting the above strength model with the data of concretes with and without additional binder, these models can be built as follows (in MPa)

Model 1. Three parameter model (without efficiency factors)

$$
f_{c}^{\prime}=(3.065 \cdot \ln T+4.424) \cdot\left(\frac{W+S P}{C+S+F}\right)^{-1.25}
$$

Model 2. Five parameter model (with constant efficiency factors)

$$
f_{c}^{\prime}=(3.313 \cdot \ln T+4.448) \cdot\left(\frac{W+S P}{C+0.867 \cdot S+0.802 \cdot F}\right)^{-1.224}
$$

Model 3. Night parameter model (with various efficiency factors)

$$
f_{c}^{\prime}=(3.078 \cdot \ln T+4.493) \cdot\left(\frac{W+S P-17.2}{C+0.848 \cdot S+f_{k_{F}} \cdot F}\right)^{-1.124}
$$

where

$$
k_{F}=f_{k_{F}}(T, R)=1.25+0.140 \cdot \ln T-3.9 \cdot R+2.75 \cdot R^{2}
$$

The root of mean squared error (RMSE) was adopted to provide a measure of the performance of strength models. Table II shows that the value of RMS errors are 1123, 1084, and 1040 psi for Model 1, Model 2 and Model 3, respectively Moreover, the coefficient of determination $\left(\mathrm{R}^{2}\right)$ was adopted as a measure of how well the independent variables considered account for the measured dependent variable. In principle, the higher the $\mathrm{R}^{2}$ value is, the better the prediction relationship will be. It was found that the $\mathrm{R}^{2}$ values are 0.789 , 0.802, and 0.812 for Model 1, Model 2 and Model 3, respectively. These indicate a good correlation between the independent variables and the measured dependent variable. TABLE I: DETAILS OF CONCRETE DATA

\begin{tabular}{|c|c|c|c|c|}
\hline & Average & STD & Min & Max \\
\hline Cement & 281.2 & 104.5 & 102.0 & 540.0 \\
\hline GBFS & 73.9 & 86.3 & 0.0 & 359.4 \\
\hline Fly ash & 54.2 & 64.0 & 0.0 & 200.1 \\
\hline Water & 181.6 & 21.4 & 121.8 & 247.0 \\
\hline SP & 6.2 & 6.0 & 0.0 & 32.2 \\
\hline CA & 972.9 & 77.8 & 801.0 & 1145.0 \\
\hline FA & 773.6 & 80.2 & 594.0 & 992.6 \\
\hline $\begin{array}{c}\text { Fly } \\
\text { ash/B }\end{array}$ & 0.139 & 0.169 & 0.000 & 0.552 \\
\hline W/B & 0.484 & 0.233 & 0.269 & 0.900 \\
\hline
\end{tabular}

TABLE II: EVALUATION OF COMPRESSIVE STRENGTH MODEL

\begin{tabular}{|c|c|c|c|}
\hline Model & $\begin{array}{c}\text { RMSE } \\
(\mathrm{MPa})\end{array}$ & $\begin{array}{c}\text { Absolute Error } \\
\text { Percentage }\end{array}$ & $\begin{array}{c}\text { Coefficient of } \\
\text { Determination }\end{array}$ \\
\hline Model 1 & 7.74 & $22.6 \%$ & 0.789 \\
\hline Model 2 & 7.47 & $21.5 \%$ & 0.802 \\
\hline Model 3 & 7.24 & $20.6 \%$ & 0.812 \\
\hline
\end{tabular}

\section{Discussions}

To explore the efficiency factor of fly ash, the curves of replacement percentage versus the efficiency factor at age 3 , 28, 365-day are drawn in Fig. 1.

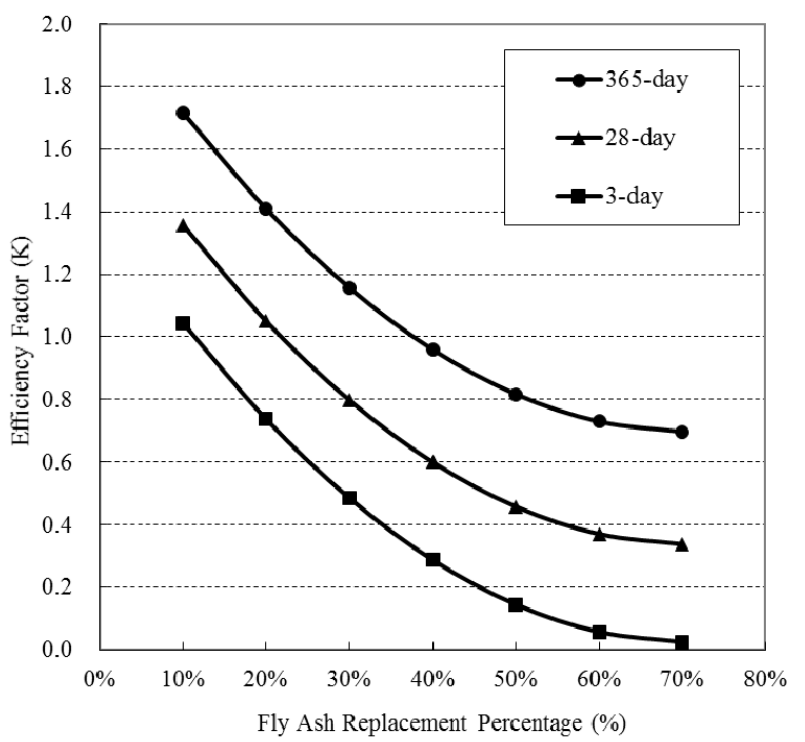

Fig. 1. Efficiency factor of fly ash derived from the efficiency factor model

It can be found that when the age is 28-day, the efficiency factors at replacement percentages 10, 20, 30, 40, 50, 60 and $70 \%$ were found to be $1.36,1.05,0.80,0.60,0.46,0.37$ and 0.34 , respectively.

When the replacement percentage is $30 \%$, the efficiency factors at age $3,7,14,28,56,90,180$ and 365-day were found to be $0.48,0.60,0.70,80,0.89,0.96,1.06$, and 1.16 , respectively.

It was observed that the overall cementing efficiencies of fly ash varied from a value of about $0.29-0.74,0.41-0.86$, $0.50-0.95,0.60-1.05,0.70-1.15,0.76-1.21,0.86-1.31$, and 0.96-1.41 for replacement percentages ranging from $20-40 \%$, 
at the $3,7,14,28,56,90,180$ and 365 days studied.

In Model 2 and Model 3, the efficiency factor values of GBFS are 0.867 and 0.848 . In Model 2, the efficiency factor of fly ash is 0.802 . The efficiency factor of GBFS is greater than that of fly ash.

\section{CONCLUSIONS}

Research efforts over the past many decades towards an effective utilization of fly ash in concrete do not seem to have led to a quantitative understanding of the efficiency of fly ash as a mineral admixture, particularly because of the vast variation in the water-binder ratio and the different levels of replacements adopted. Moreover, using high volume fly ash to replace cement, early strength of the concrete may be not enough to satisfy the demand.

This paper is an effort directed towards a specific understanding of the efficiency of fly ash in concrete, considering the strength to age and percentage of replacement, under the vast variation in the water-binder ratio. To overcome the two disadvantages of traditional decomposition approaches, a novel unification approach had been conducted. In this approach, using nonlinear regression and optimization technique, the compressive strength model and the efficiency factor model can be generated at the same time. That is, the efficiency factor model is a part of the compressive strength model.

The efficiency factor model generated by unification approach could be helpful in the design of fly ash concretes at different age, at different replacement percentage, and different water-binder ratio with greater confidence. However, these efficiency values were only the average values at the different percentages of replacement for ordinary Portland cement, normal type of aggregates and normal curing conditions.

\section{ACKNOWLEDGMENTS}

This study is sponsored by the National Science Council of the R.O.C. (Taiwan) (Project No: NSC-101-2221-E-032
$-044)$.

\section{REFERENCES}

[1] I. C. Yeh, "Modeling of strength of high performance concrete using artificial neural networks," Cement and Concrete Research, vol. 28, no. 12, pp. $1797-1808,1998$

[2] I. C. Yeh, "Modeling concrete strength with augment-neuron networks," ASCE, Journal of Materials in Civil Engineering, vol. 10, no. 4, pp. 263-268, 1998

[3] I. C. Yeh, "Design of high performance concrete mixture using neural networks," ASCE, Journal of Computing in Civil Engineering, vol. 13, no. 1 , pp. 36-42, 1999.

[4] A. Duran-Herrera, C. A. Juarez, P. Valdez, and D.P. Bentz, "Evaluation of sustainable high-volume fly ash concretes," Cement and Concrete Composites, vol. 33, no. 1, pp. 39-45, 2011.

[5] G. Hannesson, K. Kuder, R. Shogren, and D. Leman, "The influence of high volume of fly ash and slag on the compressive strength of self-consolidating concrete," Construction and Building Materials, vol. 30, pp. 161-168, September 2012.

[6] K. Kuder, D. Lehman, J. Berman, G. Hannesson, and R. Shogren, "Mechanical properties of self consolidating concrete blended with high volumes of fly ash and slag," Construction and Building Materials, vol. 34, pp. 285-295, September 2012.

[7] K. G. Babu and V. S. R. Kumar "Efficiency of GGBS in concrete," Cement and Concrete Research, vol. 30, no. 7, pp. 1031-1036, 2000.

[8] K. G. Babu and G. S. N. Rao "Efficiency of fly ash in concrete with age," Cement and Concrete Research, vol. 26, no. 3, pp. 465-474, 1996.

[9] B. Abdelkader, K. El-Hadj, and E. Karim, "Efficiency of granulated blast furnace slag replacement of cement according to the equivalent binder concept," Cement and Concrete Composites, vol. 32, no. 3, pp. 226-231, March 2010.

[10] H. Cho and N. Jee, "Prediction model for cementing efficiency of fly ash concrete by statistical analyses," Advanced Materials Research, vol. 250, pp. 1293-1296, 2011.

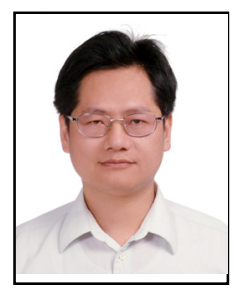

I-Cheng Yeh is a professor in the Department of Civil Engineering, Tamkang University in Taiwan. He received his $\mathrm{PhD}$ in Civil Engineering from the National Cheng Kung University, Republic of China (Taiwan) in 1992. He was awarded ASCE Best Paper Award, Journal of Materials in Civil Engineering in 1999. His current research interests include artificial neural networks and genetic algorithms, and their applications in materials. 